\title{
MILITARY ENVIRONMENTAL LITERACY IN THE SOUTH AFRICAN ARMY
}

\author{
HAP Smit, Department of Military Geography, \\ Stellenbosch University \\ JH van der Merwe, Research Fellow, Centre for Geographic \\ Analysis, Stellenbosch University
}

\begin{abstract}
Traditional military activities, such as fighting wars, are inherently destructive. Modern militaries undertake a diverse range of military activities, use large areas for military training and operational purposes, and are confronted with a global focus on environmentally responsible behaviour. These conditions compel militaries to ensure that soldiers display the correct attitude toward, behaviour in and knowledge about the diverse physical, social and cultural environments they occupy and on which they have an effect. Globally, and in South Africa, this is not only a moral obligation but a legal imperative too.
\end{abstract}

The aim of this article is to report on the military environmental literacy (MEL) (attitude, behaviour and knowledge regarding the environment in which the military operate) of the members of the South African Army (SA Army). To achieve this aim, existing environmental questionnaires were evaluated to ascertain their suitability for use in an SA Army context. None of them was usable to appraise MEL in a SA Army context effectively. Consequently, an iterative process was initiated to develop a tailor-made, valid, reliable and organisation-specific questionnaire to assess MEL in the SA Army.

A stratified sample was procured from the nine different formations of the SA Army. Twenty-five units situated throughout South Africa were selected. Of the 1203 questionnaires distributed to the units, $1090(90,6 \%)$ usable questionnaires were returned.

The returned questionnaires were scanned, and the data was extracted using Formware software. Analysis of variance was performed for the variables, and Fisher's least significant difference post hoc tests were performed for instances where the data rendered significant differences. Pearson correlation coefficients were calculated to analyse the continuous data to determine differences. The qualitative data was analysed using content analysis to interpret the military environmental narrative. 
For all three components of MEL - attitude, behaviour and knowledge respondents recorded high scores. The composite MEL denotes a high level of MEL for soldiers of the SA Army. Attitude, behaviour and knowledge scores were recorded for rank, gender, age, time employed in the South African Department of Defence (DOD), deployment experience, home language, exposure to environmental positions in the Army, environmental and geography education, and level of general education. The correlation between the components was also determined to indicate the possible influence of each component on the other components. These results are supported by those of the qualitative analysis where content analysis was used to construct the military environmental narrative.

\section{Environmental literacy and the military}

\section{When elephants do battle, the grass gets trampled: Kikuyu saying ${ }^{1}$}

This Kikuyu maxim recognises that large antagonists cannot tackle one another without inevitable cost to the environment. In the modern military sense, the elephants of the Kikuyu represent the armies of opposing nations in operation. However, it is a fact that even during peacetime, military activities such as training, weapons testing and routine activities could cause significant damage to the environment if not properly conducted. The DOD operates on and controls large tracts of land all over South Africa. To use and maintain this land in an environmentally sustainable and responsible way is a constitutionally derived organisational imperative. The DOD has a long history of formal environmental management, as evidenced by the first instruction to formulate guidelines for environmental management in the then South African Defence Force since 1977. ${ }^{2}$ The National Environmental Management Act No. 107 of 1998 (NEMA) eventually obligated all scheduled organs of state with functions that affect the environment, including the DOD, to develop an Environmental Implementation Plan (EIP). Since the promulgation of NEMA, two EIPs for defence (in 2001 and 2008) have seen the light, and a variety of internal directives testify to the apparent sincerity of the environmental commitment of the DOD.

However, no evidence of the effectiveness of these plans and policies in influencing the day-to-day activities of members of the South African National Defence Force (SANDF) exists. The policies merely reflect command concern and not actual evidence of implementation or the effect of the policies and plans on the environmental performance of members of the SANDF. The study on which this article reports, probed the reciprocal effect, or lack thereof, of DOD environmental policies and plans on the environmental performance of members of the DOD.

\section{Environmental literacy and military environmental literacy}

Precise definition has eluded the term 'environmental literacy' (EL) since the late 1960s. ${ }^{3}$ The concept is complex in nature ${ }^{4}$ and encompasses numerous and diverse meaningful components - a term used here when referring to three generally recognised elements of environmental literacy, namely attitude and behaviour toward 
and knowledge of the environment - in accordance with the broad terminological consensus in the literature. ${ }^{5}$ The term 'scale' is used when referring to the subdivision of the questionnaire where a particular component of MEL is tested. ${ }^{6}$ It may include beliefs relating to, opinions about, perceptions of and social values relating to the environment. Conceptual guidance on comprehending the different components of EL is elaborated by a host of researchers. ${ }^{7}$ Despite the lack of a precise definition of EL as a concept, a widely accepted Roth's working definition ${ }^{8}$ has been adopted by most researchers in the field. ${ }^{9}$ Roth defined EL as an individual's knowledge about and attitude toward the environment and environmental issues, skills and motivation possessed in working toward the resolution of environmental problems, and active involvement in working toward the maintenance of dynamic equilibrium between the quality of life and the quality of the environment. ${ }^{10}$ Roth has suggested a helpful model that postulates three different levels on a continuum of increasing EL:

- The first level is 'nominal environmental literacy', which implies a basic understanding of environmental processes and a developing awareness of and sensitivity toward environmental issues.

- At the next level, 'functional environmental literacy', a broader understanding and knowledge of the nature and interactions between humans and natural systems are registered.

- The third level, labelled 'operational environmental literacy' signposts those who have moved beyond functional literacy, routinely evaluate actions, and take action to improve or sustain a healthy environment.

This model therefore postulates a progression through the levels of EL in stages that include low-end awareness, through concern and understanding to eventual action at the high end. Literacy does not necessarily develop through a linear process, so action might, for instance, precede understanding. ${ }^{11}$

It is contended here that within the DOD, a specific military culture, ethos and professional conduct has become established - a statement emphatically corroborated by research. ${ }^{12}$ The military culture certainly differs significantly from civilian conduct and practice and poses unique problems, offers opportunities and requires specific skills in managing the environment in the military. Consequently, the military environment requires a unique definition to MEL effectively. Godschalk distinguishes between Military Integrated Environmental Management applied in the DOD and Integrated Environmental Management adopted and applied by civilian enterprises. ${ }^{13}$ Appropriately, the term 'military environmental literacy' (or MEL) distinguishes between military-specific environmental literacy and its civilian counterpart.

These definitions are modified and combined in this article to formulate an operational definition that reflects the military context applicable to the South African Army, namely MEL as the nature and level of the attitude toward, knowledge about, and behaviour in and toward the environment in which the military operates. 


\section{Attitude, behaviour and knowledge as components of MEL}

Generally, 'attitude' is "a way of thinking or feeling about someone or something". ${ }^{14}$ 'Environmental attitude' thus applies to "general feelings toward ecology and the environment, feelings and concerns for specific environmental issues, and feelings toward acting to remedy environmental problems". ${ }^{15}$ Environmental attitude can also be defined as "a psychological tendency expressed by evaluating the natural environment with some degree of favour or disfavour". ${ }^{16}$ The operational definition of military environmental attitude (MEA) therefore reflects that it is a general feeling of favour or disfavour toward the military environment, for example the environment in which the military operates.

According to Hawker, behaviour is the "way in which someone or something behaves", i.e. typical conduct, action or deeds under specific circumstances. ${ }^{17}$ Chao describes environmental behaviour as to "act toward the environment", ${ }^{18}$ while Kollmus and Agyeman refine matters by defining pro-environmental behaviour as "behavior that consciously seeks to minimize the negative impact of one's actions on the natural and built world". ${ }^{19}$ Bamberg and Möser expand and describe proenvironmental behaviour as "a mixture of self-interest (e.g. to pursue a strategy that minimises one's own health risk) and of concern for other people, the next generation, other species, or whole ecosystems (e.g. preventing air pollution that may cause risks for others' health and/or the global climate)." ${ }^{20}$ Military environmental behaviour (MEB) is therefore defined as a demonstration of how one acts toward or in the military environment in which the military operates.

Generically, knowledge (about something) is the "information and skills gained through experience or education". ${ }^{21}$ Vincente-Molina, Fernández-Sáinz and IzagirreOlaizola concur with this argument, ${ }^{22}$ while Dodd, Laverie, Wilcox and Duhan distinguish between "objective or actual knowledge (what a person actually knows about a product, issue or object) and subjective or perceived knowledge (what a person thinks he/she knows)" ${ }^{23}$ In this research, objective or actual knowledge about the environment was assessed through the military environmental questionnaire. Military environmental knowledge (MEK) is operationalised as the ability to identify a number of concepts and behaviour patterns related to the military environment, i.e. the environment in which the military operates.

This trichotomy of affective, behavioural and cognitive components (MEA, MEB and MEK) constitutes the construct of MEL, the subject of this article.

\section{Developing a questionnaire to survey MEL in the SAArmy}

The primary objective of the MEL research reported on here entailed the development of a questionnaire through the formal processes of draft development, panel scrutiny and pilot testing. The early versions of the questionnaire could not be structured satisfactorily because of undue focus on identification of the most relevant questions, and they were too long. Researchers at the US Military Academy at West 
Point and the Centre for Statistical Consultation (CSC) at Stellenbosch University 'sound-boarded' procedures to ensure a statistically valid product suitable for gathering meaningful quantitative and qualitative data.

\section{The MEL questionnaire}

A panel of experts was convened on 5 May 2011 to evaluate the final version of the questionnaire. Following a meeting at an international conference of military geoscientists, a final valid and reliable instrument was constructed for live testing by a convenience sample of 15 military geography first-year students at the South African Military Academy (SAMA). The outcomes of the test were used to improve questionnaire design. The final pilot questionnaire was language edited by a military language practitioner and prepared for direct electronic coding by means of Formware software and printed.

The final questionnaire was pilot tested on 30 August 2011 at the SAMA in Saldanha, yielding 153 usable questionnaires. Formware delivered an Excel table of the results, which were used to test the validity and reliability of the attitude and behaviour scales. Analysis of item difficulty and item discrimination of the knowledge scale detected questions for removal. A total of 22 items $(34,4 \%)$ were removed during this process. The final MEL questionnaire (Table 1) includes an introductory letter and an informed consent form.

Table 1. The structure and content of the final MEL questionnaire

\begin{tabular}{|c|c|c|}
\hline \multicolumn{2}{|r|}{$\begin{array}{l}\text { STRUCTURAL } \\
\text { ELEMENT }\end{array}$} & CONTENT \\
\hline \multicolumn{2}{|c|}{ Letter of introduction } & $\begin{array}{l}\text { Explanatory information for the respondents to enable them to } \\
\text { make an informed decision about participation in the survey. }\end{array}$ \\
\hline \multirow{3}{*}{ : } & Attitude scale & $\begin{array}{l}\text { Eliciting responses regarding attitude } \\
15 \text { Likert-type items }\end{array}$ \\
\hline & Behaviour scale & $\begin{array}{l}\text { Eliciting responses regarding self-reported behaviour } \\
13 \text { Likert-type items }\end{array}$ \\
\hline & Knowledge scale & $\begin{array}{l}\text { Eliciting responses to military environmental knowledge items } \\
14 \text { multiple-choice items }\end{array}$ \\
\hline : & Open-ended items & $\begin{array}{l}\text { Allow respondents to motivate their responses and establish an } \\
\text { environmental narrative } \\
\text { Six open-ended items (First two items correspond to the } \\
\text { attitude section in the quantitative part of the questionnaire, } \\
\text { two to the behaviour section and two to the knowledge section) }\end{array}$ \\
\hline \multicolumn{2}{|c|}{$\begin{array}{l}\text { Biographical and } \\
\text { service history section }\end{array}$} & $\begin{array}{l}\text { Eliciting biographical and service history information } \\
16 \text { items }\end{array}$ \\
\hline \multicolumn{2}{|c|}{$\begin{array}{l}\text { Informed consent } \\
\text { form }\end{array}$} & $\begin{array}{l}\text { Explanation of the implications of participation in the research. } \\
\text { Signature required from a respondent to participate. }\end{array}$ \\
\hline
\end{tabular}


Three sections dealing with attitude, self-reported behaviour and knowledge respectively, constitute the first part of the questionnaire. A section of open-ended items was included to afford respondents the opportunity to motivate their answers. The last section elicits details about the biographical and service history of respondents. The final, SA Army-specific, valid and reliable MEL questionnaire was printed and administered in the survey to establish the MEL of SA Army members.

\section{The MEL survey}

The final MEL questionnaire was administered to a sample of members from SA Army units. A stratified sample of units, representative of the size and number of units in each of the nine SA Army formations ${ }^{24}$ was drawn using the RAND function in Microsoft Excel. Twenty-five active military units were selected from the 90 active units of the SA Army. To ensure meaningful results at formation level, at least 50 respondents were selected from each formation. Although 1000 respondents would have been sufficient, to cater for non-response, 1203 respondents were selected to participate in the survey.

Following the unit sampling, each commanding officer of the selected units was entreated by letter for permission to do the survey and to supply a name list of unit members. Names were randomly selected from the lists, stratified proportionally by gender and rank. Only members with ranks below that of colonel were included to ensure anonymity and avoid compromising the ethical integrity and validity of the research. It is noteworthy that this research focused on the viewpoints of ordinary soldiers, not those of managers.

Dates, times and venues were arranged for the surveys. Originally, it was intended that a research team would administer all the surveys to ensure high return rates and allow for personal supervision by the researcher. The practical realities of the spatial spread of units throughout South Africa, coupled with an inability to establish suitable dates and times forced a re-evaluation of the intended procedures. The practical resolution was the recruitment of 11 local research supervisors who, after careful briefing, executed the surveys. Respondent selection was centralised and the names of selected members were mailed to the units to arrange attendance. Questionnaires, informed consent forms, final instructions on how to conduct the survey, pens and a reward lollipop for each respondent were couriered to the research assistants and afterwards the completed questionnaires were couriered back to the SAMA.

This system functioned effectively and all the surveys were completed between 30 May and 27 September 2012. Of the 1203 questionnaires dispatched to the units, the survey process rendered 1112 returned questionnaires $(92,4 \%$ of the questionnaires dispatched) of which $22(2 \%)$ were unusable. This yielded an exceptional 1090 $(90,6 \%)$ usable questionnaires. The sample assured representative coverage of the formations, with only two failing to do so by inconsequential margins. 
Subsequent to quality control, the questionnaires were scanned to yield an Excel spreadsheet database for further analysis. The electronic database was cross-checked against the paper copies of the completed questionnaires to ensure data integrity. Only 54 discrepancies $(0,07 \%)$ in 76300 items were uncovered during this process. This testifies to the integrity of the survey and data management. After rectification, recoding of the data and data clean-up of the database was analysed by LISREL 8.8 software in consultation with the CSC. Pairwise deletion of cases was done to deal with missing data. These processes ensured a database of extremely high integrity.

\section{Assessing the MEL of South African Army soldiers}

The quantitative data for the study was derived from the first three sections of the questionnaire. In the first two sections, Likert-type questions with a five-point response range $(1=$ strong agreement, $2=$ agreement, $3=$ neutrality, $4=$ disagreement and $5=$ strong disagreement) were employed, while the third section tested the knowledge of respondents by means of multiple-choice questions. The discrete data was probed for relationships through analysis of variance testing, while, for the same reason, Pearson product-moment correlation coefficients were calculated for the continuous variables.

The first questionnaire scale assessed the attitude of respondents toward the environment in which the military operates. Fifteen items tested the attitude of respondents from preformulated statements regarding the environment in which the military operates. Respondents were required to rate statements on the five-point Likert-type scale mentioned above. In the behaviour scale, 13 items rated the selfreported behaviour of respondents toward the environment in which the military operates on the same five-point Likert-type scale. In the knowledge scale, 14 multiplechoice items assessed the knowledge of respondents toward the environment in which the military operates. Twelve items offered five scale choices, while two had only three choices. All items allowed "I do not know" as an option to capture uncertainty or a lack of knowledge.

Several statistical methods were employed to analyse questionnaire responses. Commencing with simple descriptive statistics (mean, mode, median) and graphic display (histograms, box plots, bar plots, pie charts) analyses were elevated to more advanced inferential statistics and statistical modelling for which methodological guidance was gleaned from prominent sources. ${ }^{25}$

Analysis of variance (ANOVA) was calculated for discrete variables (e.g. gender, formation) to assess their relationships with attitude, behaviour and knowledge. In experimental research, ANOVA is used as an overall test of whether group means differ significantly. This technique gives an $F$-statistic (named in honour of Sir Ronald A Fisher who developed the analysis of variance as a statistical technique in 1918) ${ }^{26}$ where low values ( $F$ close to 1$)$ indicate similarity, which implies limited ability to make predictions from the observed data. Higher values ( $F$ larger than 1$)$ indicate dissimilarity, implying the ability to make predictions from the observed data ${ }^{27}$. $P$-values smaller than 0.05 indicate that the hypothesis that the observed variables are 
all the same, can be rejected. For example, a $p$-value smaller than 0.05 indicates that in at least one case, the attitude of that formation will differ from the rest. However, after determining that significant differences exist, it had to be determined which formations differ significantly from one another. This was done through post hoc testing. ${ }^{28}$

Statistically significant differences between variables can be determined by conducting post hoc or a posteriori testing. Both terms refer to the fact that the testing was done 'after the event' where the 'event' refers to a significant result for ANOVA. ${ }^{29}$ Different types of post hoc tests, such as Sheffé's method, the Tukey test and the Bonferroni's test are but a few types. ${ }^{30}$ The Statistical Package for the Social Science (SPSS) performs 18 types of post hoc tests. ${ }^{31}$ In the MEL study, Fisher's least significant difference (LSD) tests were performed on the data to determine statistically significant differences between variables.

Because the variables service duration, age, highest level of education completed and highest level of geography education completed are continuous, they cannot be analysed in the same way as the discrete variables. Pearson product-moment correlation coefficients were calculated for the discrete variables. Correlation analysis assesses the association between two variables as well as the strength and direction (positive or negative) of the association. Correlation coefficients range between -1 (strongly negative) and +1 (strongly positive), while 0 denotes no association. ${ }^{32} \mathrm{~A}$ $p$-value below 0.05 indicates that the association is statistically significant. Although there is no scientific reason for the choice of 0.05 as indicator value, it is the standard significance level for probability that most researchers use. ${ }^{33}$ To assess the relationship between the scales attitude, behaviour and knowledge, the correlation between the different scales was computed following international best practice. ${ }^{34}$ The results were presented by means of scatterplots for the correlations between attitude and behaviour, knowledge and attitude, and knowledge and behaviour to probe for relationships between the components of MEL.

Following Falissard, ${ }^{35}$ composite scores were calculated for each of the three questionnaire scales. The arithmetic means for these scales were calculated to summarise the attitude, behaviour and knowledge levels of respondents or the subcategories of respondents. However, combining the components of environmental literacy (EL) into a single, composite EL score was uncommon ${ }^{36}$ and lacked a strict scientific basis. ${ }^{37}$ A composite EL score does have practical value, such as enabling comparison between similar studies or repeat surveys of the same population, something for which this research hope to form the basis. As such, a composite MEL score was calculated using the three components of MEL. McBeth et al. (2008) calculated a composite EL score for the National Environmental Literacy Project (NELP), a baseline study of middle-grade students in the United States. ${ }^{38}$ Their method entailed the construction of composite scores for EL components transformed into scores out of 60 to ensure equal representation of all the components. ${ }^{39}$ This method was also used by Karatekin in a study of the EL levels of student teachers in Turkey, ${ }^{40}$ and it was consequently adapted for use in the reported MEL research. 
During the process of content analysis, response categories were identified primarily during initial data scrutiny. However, response categories that had been identified during the literature study, compilation of the questionnaire and data collection process were also employed. The items in the open-ended section require respondents to agree or disagree with a statement or to answer positively or negatively to an item. After posting a positive or negative response, respondents had to give reasons for their answer. As a first step in the coding process, responses to each item were collated in a separate data set for each item. The responses to the first part of each of the items in each data set were counted and described. The data sets were printed to facilitate the reading and coding of responses. The printed data sets were used to expand the response categories identified during the literature study, the compilation of the questionnaire and the data collection process. Responses were then preliminarily coded according to the identified response categories.

During each step in the content analysis, the responses were read either partially or in total, so leading to the 'thicker'41 or fully descriptive meaning of the responses - the primary goal of qualitative research. ${ }^{42}$ Tables were compiled that enumerated the total number of responses, non-responses and typical responses to items. Typical response recognition ensures authenticity of the results and avoids the imposition of researcher interpretations on the responses. ${ }^{43}$ At the conclusion of the analysis, the results were described and interpreted to identify salient response trends - the normal research conclusion. ${ }^{44}$

\section{MEL in the South African Army}

The results derived from the analysis of the survey data are presented and discussed to clarify the findings of the survey. The discussion is structured according to the components of MEL, namely MEA, MEB and MEK. This is followed by the correlation results, the composite MEL and the MEL narrative.

\section{Military environmental attitude}

The general military environmental attitude (MEA) to the environment in which the military operates is positive as indicated by the combined mean of 1,8 for the (five-point) MEA scale. The average response for attitude items on the Likert-type scale measured between 'agree strongly' (1), and 'agree' (2) - a positive result.

The attitude values varied according to the socio-demographic, education and training, and service profiles of the respondents.

Four socio-demographic independent variables, namely age, gender, marital status and home language were examined for causal relationships with MEA. Only home language rendered a statistically significant relationship, with age, gender and marital status having no influence on the MEA of respondents. These findings have two important implications. First, it substantiates the military-specific lens of the survey instrument, which negated the traditional influence of gender and marital roles through the specificity of the military workplace environment. Second, the 
significant relationship between home language and attitude accentuates the reality that the military environmental message has to be very carefully packaged in the multi-language, multicultural and multi-ethnic SA Army to be fully effective.

The examination of the effect of education and training variables (general education, geography education and environmental education and training) on MEA generated surprising results. Contrary to the findings reported in the literature on environmental attitude, general education level and geography subject education had no statistically significant relationship with MEA. However, respondents who had completed military environmental courses registered a significantly more positive attitude to the environment than those who had not attended any. These results confirmed the dissimilarity between MEA and general environmental attitude - a premise of this MEL survey. Consequently, attitude is not influenced by the chosen independent variables in the normal manner reported in civilian EL literature. It is noteworthy that focused military environmental courses improved the MEA of soldiers, while general and geography education did not.

The influence of service profile variables (formation membership, rank, environmental management, service duration and deployment experience) has similarly been probed for relationships with MEA. Two large formations, Infantry and Engineers, recorded notably lower, while two small formations, Training and Air Defence Artillery, recorded notably higher MEA values than the average formation. The sheer size of the two large formations might preclude quick MEA interventions, but successful interventions would affect the general MEA of the whole SA Army positively. Training and Air Defence Artillery formations are small formations where the presence of suitably qualified 'champions' drive environmental education and training, which influenced the MEA of members positively.

Using military rank as indicator of MEA, the group with the lowest rank of riflemen, recorded the least positive attitude outcomes, with no statistically significant difference between other rank groups. This underlines the need for intervention to foster good environmental attitudes early in the careers of SA Army soldiers, something clearly lacking at present.

Respondents with some form of previous or current military environmental experience recorded better environmental attitudes than those without any such environmental responsibilities. This is a significant finding confirming that formal military environmental courses and environmental management responsibilities do improve MEA in the workplace. Service duration and deployment experience produced no statistically significant results, implying that these two factors did not improve or decrease the MEA of soldiers. The finding that internationally deployed soldiers had no distinctly better MEA revealed a serious deficiency in military environmental education and training in the SA Army, and underscores the urgent need to reassess 'pre-deployment' interventions. The findings on MEA suggest that the general MEA of soldiers in the SA Army is good and that the unique nature of the military environmental environment is confirmed. 


\section{Military environmental behaviour in the South African Army}

The general environmentally conscious behaviour toward and in the environment in which the military operate is evidenced by the combined mean of 1,8 recorded for the military environmental behaviour $(M E B)$ scale. This is a positive result, indicating that most soldiers recorded "agree strongly", or "agree" responses to the items in the questionnaire. The MEB of soldiers varied according to their socio-demographic, education and training, and service profiles.

The socio-demographic profile variables marital status and home language showed statistically significant relationships with MEB whereas age and gender did not. Based on these findings, two implications are worthy of note. The military focus of the questionnaire negates the influence of traditional gender roles on behaviour because it investigates experiences in the workplace and not the civilian environment. The significant relationship between home language and MEB again confirms that in the SA Army environment, the military environmental message must take multilanguage, multicultural and multi-ethnic realities into account to be effective.

Regarding education and training, it was unexpected that level of general education and geography education would have no statistically significant influence on MEB. Respondents who had completed military environmental courses and those who did not also displayed similar behaviour values. These results confirm that MEB and general environmental behaviour are dissimilar - a basic premise of the MEL research. Consequently, MEB is also not influenced by the chosen education and training variables in the same manner as what is reported in civilian EL literature. The anomaly here is that focused military environmental courses improved the MEA of soldiers, but not their behaviour.

Regarding environmental behaviour and the soldiers' service profile, the three largest formations - Infantry, Support and Signal formations - recorded the least positive results, while two small formations, Training and Air Defence Artillery, recorded the most positive MEB results. These results correspond with the MEA results, and the rationale for this holds true for MEB as well. The former three formations constitute $72 \%$ of the total number of SA Army soldiers. Because of their dominant size, military environmental interventions would not only improve the MEB in these poorly performing formations, but also have a positive influence on the general MEB of the whole SA Army.

The investigation of military rank as an indicator of MEB found no statistically significant differences between soldiers with different ranks. This is contrary to the findings regarding attitude where riflemen - the lowest rank - recorded the least positive attitude results, and no statistically significant difference was found between the other rank groups. This anomaly - riflemen reporting the least positive attitude but recording no difference between themselves and other ranks in terms of behaviour can best be explained in terms of the command-and-control structure in the SA Army. Soldiers are taught to follow orders, even though they may not subscribe to them. If this postulation is accurate, early intervention to foster good environmental behaviour in SA Army soldiers is required. 
No significantly different results were obtained for soldiers with current or past military environmental responsibilities and those without. This contradicts the MEA findings that respondents with some environmental responsibility recorded better results than those without such responsibility. Better attitudes resulting from having environmental responsibilities did not translate into better environmental behaviour, a finding supported by the literature. Finally, time served in DOD employment yielded a statistically significant result, but with the slight correlation indicated an almost negligible relationship.

Contrary to the findings regarding MEA, soldiers who had been deployed manifested better environmental behaviour. The explanation can most likely be found in subjective norm behaviour where the expectation that the significant other's expectation of a certain behaviour leads to the expected behaviour. Prior to deployment, soldiers attend special environment-oriented lectures, which probably inspire them to exhibit pro-environmental behaviour despite their not having a corresponding positive environmental attitude.

\section{Military environmental knowledge in the South African Army}

The respondents registered a mean military environmental knowledge (MEK) score of $65 \%$, which is an appropriate overall achievement if compared to civilian environmental knowledge scores of, on average, $60,2 \%$ reported in literature. ${ }^{45}$ The finding attests to satisfactory environmental knowledge among South African soldiers. MEK scores varied from the socio-demographic, education and training, and service profiles of the respondents.

Two variables comprising the respondents' socio-demographic profile, namely, gender and home language generated statistically significant relationships, while age and marital status had no influence on the MEK of the respondents. The established relationships between knowledge, gender and home language accord with findings reported in literature. This presents a challenge to the SA Army to package its environmental message in a gender- and language-friendly manner if it is to be effective and successful.

Consistent with findings reported in the literature on the relationship between the education and training profile of respondents, higher levels of general education, more favourable levels of geography education and more military environmental education and training were found to influence MEK in a statistically significant positive way. However, this does not accord with the findings for MEA and MEB.

Regarding service profile, the largest formation, the Infantry, recorded the least positive MEK result, while two small formations, Air Defence Artillery and Training had the highest level of MEK, the same as reported for MEA and MEB. Again, the large size of the Infantry formation implies that military environmental interventions would improve the behaviour of soldiers in this formation, but also have a beneficial influence on the general MEK of the whole SA Army. 
Concerning the rank of soldiers as indicator of MEK, it transpired that junior and senior officers posted the most positive MEK results and riflemen, the least positive. It is again worth noting that the results regarding riflemen, if compared to civilian results, are still good.

Soldiers with experience of environmental management posted significantly better MEK results compared to respondents without such experience, while service duration and deployment experience rendered no statistically significant differences in MEK.

\section{Correlation of the three components of $M E L$}

Correlation analysis of MEA, MEB and MEK produced relationships similar to those found in the literature. The strongest correlation $(\mathrm{r}=0.56$, indicating a large effect and strong relationship) was found between attitude and behaviour. The second strongest correlation $(\mathrm{r}=0.35$, showing a medium effect and medium relationship) was recorded for knowledge and attitude, and the weakest correlation $(\mathrm{r}=0.29$ indicating a small effect and weak relationship) was found for knowledge and behaviour. All of the correlations were positive.

These associations have some important practical implications. The weakest relationship recorded between knowledge and behaviour implies that MEK does not necessarily translate into pro-environmental behaviour. The medium positive relationship between knowledge and attitude implies that a change in one may effect a change in the other, implying that improving the knowledge of soldiers could improve their attitude towards the environment. The substantial relationship between attitude and behaviour implies that by improving the attitudes of soldiers, their proenvironmental behaviour will be affected accordingly. These findings could have far-reaching consequences for military environmental education and training in that the SA Army should focus efforts not only on improving the MEK of soldiers but, more importantly, strive to foster a supportive attitude toward military integrated environmental management among its soldiers.

The evidence that correlations between pairs of MEL components are consistent with those reported in the literature on civilian studies testifies to the validity and reliability of the questionnaire designed for the MEL survey.

\section{Composite MEL of South African Army soldiers}

The composite MEL score for the SA Army registered an excellent $75 \%$. This is a high score compared to the routinely reported examples in the literature of composite MEL scores between $60 \%$ and $70 \%$. In the current study, the quantitative results of the MEL investigation produced good scores for the attitude, behaviour and knowledge scales, and an above average composite score for MEL in the SA Army. One can therefore conclude that the MEL of SAArmy soldiers is at a high level, which satisfies the primary question this research endeavoured to answer. 


\section{The military environmental narrative}

The MEL narrative was constructed from respondents' written answers to six open-ended items in the MEL questionnaire. Content analysis was used to construe the narrative. Of the respondents, 99\% indicated their agreement or not with the statement that it is important for the SA Army to protect the environment in which it operates. Although most of the reasons given for this response were either utilitarian or human-centred in nature, a substantial number of ecocentric reasons were also recorded, indicating that a superior level of environmental concern is also present in the SA Army.

On whether respondents regarded themselves as generally environmentally conscious, $90 \%$ replied in the affirmative, again testifying to the positive environmental attitude recorded in the quantitative analysis. As justification for this response, the duty of care principle and positive behaviour, such as recycling, not littering and picking up litter were cited most often. A considerable cohort of respondents named knowledge attainment as their rationale. For those who did not agree, it was a matter of lack of knowledge about military environmental issues, while a significant group also felt that exemplary military environmental conduct is not an organisational imperative of the SA Army.

When asked whether they thought that good environmental practices could improve mission success, $92 \%$ of the respondents answered that they did, but $45 \%$ gave incomprehensible reasons why they did. The reason for this failure to produce coherent responses is unclear. Among the coherent responses, the rationales given included that sustainable environmental practices will improve mission success, that the social responsibility of the SA Army is part of mission execution, and that the health of soldiers will not be imperilled during missions where good environmental practices prevail. The rationales for negative responses revolved around ignorance about the organisational imperative or that it is an impossible mandate.

An item that focused attention on the reported behaviour of respondents enquired whether they try to minimise their negative effect on the environment at their workplace. The $92 \%$ affirmative responses accorded with the high level of positive self-reported behaviour recorded in the behaviour scale. The main justifications for this referred to their attempts to use the environment responsibly, that it is an organisational imperative, and that they want to leave a legacy to future generations. These two questions again corroborated the good results posted for behaviour in the quantitative section of the questionnaire.

The item on whether the South African Army provided them with adequate environmental education and training to take care of the environment in which they operate, drew an affirmation of $62 \%$ that this is true. Of the written explanations, $57 \%$ stated that an environmental specialist regularly informed them about their potential effects on the environment, and how they could mitigate them. This testifies to the vital role of environmental services personnel in inculcating an environmental ethos 
in the SAArmy. Their influence had a major influence in the overall high level of MEL recorded in the research reported here. Contrarily, more than half of the respondents who indicated that the SA Army had not provided them with sufficient education and training, maintained that they needed more training and education. This should be welcomed as a positive result, showing a willingness to learn more about the environment in which soldiers operate. A disconcerting reason given by $31 \%$ of the respondents who felt that the SAArmy did not adequately train them in environmental protection was that they never received any environmental information. This serious allegation must be investigated by DOD management. Moreover, these are indicative of disparities in the environmental education and training received by soldiers in the various formations and a perception that environmental education and training opportunities only exist for some rank groups. Further research and intervention must be prioritised.

Asked if they had a need to learn more about the environment in which they operate, $92 \%$ declared that they needed more environmental education and training. The prominent reasons indicated a tendency toward lifelong learning and a need to know more to be able to take better care of the military environment. This further emphasises a general willingness and need to receive more environmental education and training. Fulfilment of this need by the DOD would further enhance the MEL of SA Army soldiers. The responses to these last two items endorse the high standard of MEK of the soldiers revealed in the quantitative study.

The high level of consistency in the responses throughout the questionnaire is an important indicator that the respondents answered truthfully and consistently.

The environmental narrative depicted the real-life experiences of soldiers in the SA Army, describing their experience with environmental issues in their work environment in their own words. This is a valuable measure of MEL in the SA Army.

\section{Military environmental literacy: Implications and value}

Militaries worldwide, including the SA Army, are under increasing pressure to conduct their operations in an environmentally responsible manner. This is the ethically and morally appropriate way to act, and a legal imperative, but it also makes sense from a business perspective. Military missions can be compromised by inappropriate environmental conduct, and the fallout of poor military environmental practices could remain long after conflicts or interventions have been resolved. Soldiers who have an appropriate degree of MEL could prevent this from happening. Soldiers with apposite environmental attitude, adequate knowledge and behaviour patterns that allow them to operate effectively in whatever environment they must execute their mission, will not burn religious books, destroy important cultural artefacts, ignore cultural taboos, contravene environmental laws or harm the physical environment in which they operate. Nor will they tolerate unsustainable environmental practices that may have an adverse effect on their own health and safety as well as that of the civilian population where the soldiers operate. 
Having environmentally literate soldiers is not just a luxury in the South African Army; it is an organisational imperative. Application of the findings and recommendation of this MEL research will facilitate SA Army management and Environmental Services personnel to understand MEL in the SA Army better. It will also ensure the continued building of an environmentally responsible South African DOD.

The MEL questionnaire can be used in a number of other contexts as well. By surveying soldiers both before and after they had completed environmental education and training courses, the effectiveness of these courses can be ascertained and possible inadequacies of the curricula can be identified. This will aid quality control and the improvement of the environmental education and training curricula in the SA Army. The same applies to improving the interventions aimed at deploying soldiers before and after deployment. Using the results of the current study as benchmark, follow-up surveys in the same units may indicate progress or a lack thereof in the MEL of SA Army soldiers.

With minor adaptations, the questionnaire could be used to conduct similar surveys in other armies, especially in English-speaking Africa, potentially reaching a much wider audience.

\section{Endnotes}

${ }^{1}$ G Claassen, P Muller \& M van Tonder. Die groot aanhalingsboek. Cape Town: Human \& Rousseau, 1998. 48.

${ }^{2}$ KB Godschalk. "Green soldiering: Integrated environmental management as a major contribution towards military mission achievement". Paper delivered at the 14 th International Logistics Congress, Sun City, 1998.

${ }^{3} \mathrm{~S}$ Hsu \& RE Roth. "Predicting Taiwanese secondary teachers' responsible environmental behaviour through environmental literacy variables." The Journal of Environmental Education 30/4. 1999. 11-21.

${ }^{4}$ GT Miller \& SE Spoolman. Living in the environment $\left(17^{\text {th }}\right.$ ed). Andover: Cengage Learning, 2012.

${ }^{5}$ JM Wright. "Web-based versus in-class: An exploration of how instructional methods influence postsecondary students' environmental literacy". The Journal of Environmental Education 39/2. 2008. 33-45.

${ }^{6}$ TG Teksoz, JW Boone, OY Tuzun \& C Oztekin. "An evaluation of the environmental literacy of preservice teachers in Turkey through Rasch analysis". Environmental Education Research 20/2. 2014. 202-227; S Zecha. "Environmental knowledge, attitudes and actions of Bavarian (southern Germany) and Asturian (northern Spain) adolescents". International Research in Geographical and Environmental Education 19/3. 2010. 227-240.

${ }^{7}$ E Alp, H Ertepinar, C Tekkaya \& A Yilmaz. "A survey on Turkish elementary school students' environmental friendly behaviours and associated variables". Environmental Education Research 14/2. 2008. 129-143; E Alp, H Ertepinar, 
C Tekkaya \& A Yilmaz. “A statistical analysis of children's environmental knowledge and attitudes in Turkey". International Research in Geographical and Environmental Education 15/3. 2006. 210-223; A Amarant. "An investigation into the environmental knowledge, attitudes, and behavioural intentions of elementary school students". PhD thesis. Curtin University of Technology, 2006; S Barr \& AW Gilg. "A conceptual framework for understanding and analysing attitudes towards environmental behaviour". Geografiska Annaler 89/4. 2007. 361-379; MH Ehrampoush \& MHB Moghadam. "Survey of knowledge, attitude and practice of Yazd University of Medical Sciences students about solid wastes disposal and recycling". Iranian Journal of Environmental Health, Science and Engineering 2/2. 2005. 26-30; FG Kaiser, S Wölfing \& U Fuhrer. "Environmental attitude and ecological behaviour”. Journal of Environmental Psychology 19. 1999. 1-19; NC Kibert. "An analysis of the correlations between the attitude, behaviour and knowledge components of environmental literacy in undergraduate university students". MA thesis. University of Florida, 2000; A Lopez, CC Torres, B Boyd, NJ Silvy \& RR Lopez. "Texas Latino college students' attitudes toward natural resources and the environment". Journal of Wildlife Management 71/4. 2007. 1275-1280; JL Meinhold \& AJ Malkus. "Adolescent environmental behaviours: Can knowledge, attitudes and self-efficacy make a difference?" Environment and Behaviour 37/4. 2005. 511-532; M Özden. "Environmental awareness and attitudes of student teachers: An empirical research". International Research in Geographical and Environmental Education 17/1. 2008. 40-55.

${ }^{8} \mathrm{CE}$ Roth. Environmental literacy: Its roots, evolution, and directions in the 1990s. Columbus, OH: ERIC/CSM, 1992.

${ }^{9} \mathrm{H}$ Chu et al. "Korean year 3 children's environmental literacy: A prerequisite for a Korean environmental education curriculum". International Journal of Science Education 29/6. 2007. 731-746; S Pe'er, D Goldman \& D Yavetz. "Environmental literacy in teacher training: Attitudes, knowledge, and environmental behaviour of beginning students". The Journal of Environmental Education 39/1. 2007. 45-59; A Walsh-Daneshmandi \& M MacLachlan. "Towards effective evaluation of environmental education: Validity of the children's environmental attitudes and knowledge scale using data from a sample of Irish adolescents". The Journal of Environmental Education 37/2. 2006. 13-23.

${ }^{10}$ Roth op. cit.

${ }^{11}$ Ibid., p. 26.

${ }^{12}$ A Esterhuyse. "Institutional culture: The South African military and its search for organisational stability". In F Vreÿ, A Esterhuyse \& T Mandrup (eds), On military culture. Claremont: UCT Press, 2013.

${ }^{13}$ Godschalk op. cit.

${ }^{14} \mathrm{~S}$ Hawker (ed). Oxford Paperback Dictionary, Thesaurus, and Wordpower Guide. Oxford: Oxford University Press, 2001.

${ }^{15}$ Pe'er et al. op. cit. 
${ }^{16}$ TL Milfont \& J Duckitt. The environmental attitudes inventory: A valid and reliable measure to assess the structure of environmental attitudes. Journal of Environmental Psychology 30. 2010. 80-94.

${ }^{17}$ Hawker op. cit., p. 72.

${ }^{18}$ Y Chao. "Predicting people's environmental behaviour: Theory of planned behaviour and model of responsible environmental behaviour". Environmental Education Research 18/4. 2012. 437-461.

${ }^{19}$ A Kollmuss \& J Agyeman. "Mind the gap: Why do people act environmentally and what are the barriers to pro-environmental behaviour?" Environmental Education Research 8/3. 2002. 239-260.

${ }^{20} \mathrm{~S}$ Bamberg \& G Möser. "Twenty years after Hines, Hungerford, and Tomera: A new meta-analysis of psycho-social determinants of pro-environmental behaviour". Journal of Environmental Psychology 27. 2007. 14-25.

${ }^{21}$ Hawker op. cit., p. 499.

${ }^{22}$ MA Vicente-Molina, A Fernández-Sáinz \& J Izagirre-Olaizola. "Environmental knowledge and other variables affecting pro-environmental behaviour: Comparison of university students from emerging and advanced countries". Journal of Cleaner Production 61. 2013. 130-138.

${ }^{23}$ TH Dodd, DA Laverie, JF Wilcox \& DF Duhan. "Differential effects of experience, subjective knowledge, and objective knowledge on sources of information used in consumer wine purchasing". Journal of Hospitality and Tourism Research 29/1. 2005. 3-19.

${ }^{24}$ The nine formations of the South African Army at the time of the survey were Air Defence Artillery, Armour, Artillery, Engineer, Infantry, Intelligence, Signal, Support and Training formations.

${ }^{25} \mathrm{C}$ Bless, C Higson-Smith \& SL Sithole. Fundamentals of social research methods: An African perspective. Cape Town: Juta, 2013; B Falissard. Analysis of questionnaire data with R. London: CRC Press, 2012; S McKillup. Statistics explained: An introductory guide for life scientists $\left(2^{\text {nd }}\right.$ ed). New York, NY: Cambridge University Press, 2012.

${ }^{26}$ McKillup op. cit.

${ }^{27}$ A Field. Discovering statistics using IBM SPSS statistics ( $4^{\text {th }}$ ed). Los Angeles, CA: Sage, 2013.

${ }^{28}$ Ibid.; McKillup op. cit.; D Remenyi, G Onofrei \& J English. An introduction to statistics using Microsoft Excel. Reading, PA: Academic Publishing, 2011.

${ }^{29}$ McKillup op. cit.

${ }^{30}$ Ibid.; AGW Steyn, CF Smit, SHC du Toit \& C Strasheim. Moderne statistiek vir die praktyk. Pretoria: Van Schaik, 1994.

${ }^{31}$ Field op. cit.

${ }^{32}$ Remenyi et al. op. cit.

${ }^{33}$ McKillup op. cit., p. 60

${ }^{34} \mathrm{Chu}$ et al. op. cit.; N Esa. "Environmental knowledge, attitude and practices of student teachers". International Research in Geographical and Environmental Education 19/1. 2010. 3950; EB Lee. "Environmental attitudes and information sources among African American college students". The Journal 
of Environmental Education 40/1. 2008. 29-42; M Negev, G Sagy, Y Garb, A Salzberg \& A Tal. "Environmental problems, causes and solutions: An open question". The Journal of Environmental Education 41/2. 2010. 101-115.

${ }^{35}$ Falissard op. cit.

${ }^{36}$ W McBeth. "RE: Environmental literacy scores” (mcbeth@uwplatt.edu). E-mail to H. Smit (hennies@ma2.sun.ac.za)1 February 2016.

${ }^{37}$ T Marcinkowski. "RE: Environmental literacy scores” (marcinko@fit.edu). E-mail to H. Smit (hennies@ma2.sun.ac.za)16 February 2016.

${ }^{38} \mathrm{~W}$ McBeth, H Hungerford, T Marcinkowski, T Volk \& R Meyers. "National Environmental Literacy Assessment Project: Year 1, National baseline study of middle grades students. Final report". Report to the US Environmental Protection Agency, National Oceanic and Atmospheric Administration, and North American Association for Environmental Education under Grant \#NA06SEC4690009. 2004. <http://www.oesd.noaa.gov/NAEE_Report/ Final_ NELA\%20minus\%20MSELS_8-12-08.pdf> Accessed on 1 March 2014.

${ }^{39} \mathrm{~W}$ McBeth \& TL Volk. "The National Environmental Literacy Project: A baseline study of middle grade students in the United States". The Journal of Environmental Education 41/1. 2010. 55-67; W McBeth, H Hungerford, T Marcinkowski, T Volk \& K Cifranick. "National Environmental Literacy Assessment, Phase Two: Measuring the effectiveness of North American environmental education programs with respect to the parameters of environmental literacy. Final research report". Report to the US Environmental Protection Agency, National Oceanic and Atmospheric Administration, and North American Association for Environmental Education under Grant \#NA08SEC4690026. 2011. <http://www.oesd.noaa.gov/NAEE_Report/Final_ NELA\%20minus\%20MSELS_7-02-11.pdf> Accessed on 1 March 2014.

${ }^{40} \mathrm{~K}$ Karatekin. "Comparison of environmental literacy levels of pre-service teachers". International Journal of Academic Research 5/2. 2013. 5-14.

${ }^{41}$ E Henning, W van Rensburg \& B Smit. Finding your way in qualitative research. Pretoria: Van Schaik, 2011.

${ }^{42}$ Bless et al. op. cit.; S Elo \& H Kyngäs. "The qualitative content analysis process". Journal of Advanced Nursing 62/1. 2007. 107-115.

${ }^{43}$ Bless et al. op. cit.; Negev et al. op. cit.

${ }^{44}$ SE Stemler. "An overview of content analysis". Practical Assessment, Research \& Evaluation 7/17. 2001. 1-10.

${ }^{45}$ AM Said, F Ahmadun, LH Paim \& J Masud. Environmental concerns, knowledge and practices gap among Malaysian teachers. International Journal of Sustainability in Higher Education 4/4. 2003. 305-313; Pe'er et al. op. cit.; Vicente-Molina et al. op. cit.; Karatekin op. cit. 